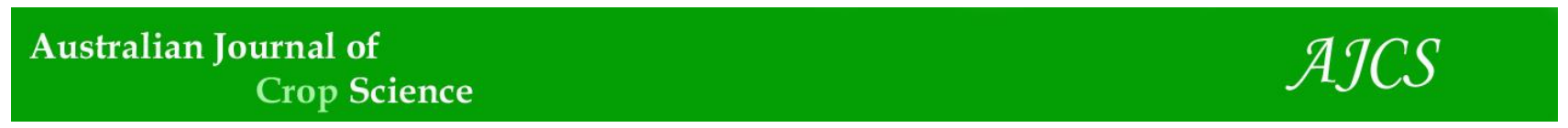

AJCS 14(07):1150-1156 (2020)

ISSN:1835-2707

doi: 10.21475/ajcs.20.14.07.p2451

\title{
Physicochemical and rheological properties of the derivatives of Ningmai 9 wheat and their relationship with sugar-snap cookie diameter
}

\author{
Pingping Zhang ${ }^{* 1}$, Jinbao $\mathrm{Yao}^{1}$, Hongxiang $\mathrm{Ma}^{1}$, Guicheng Song ${ }^{1}$ \\ Institute of Food Crops, Jiangsu Academy of Agricultural Sciences/Jiangsu Collaborative Innovation Center \\ for Modern Crop Production, 50 Zhongling Street, Nanjing, Jiangsu 210014, China
}

*Corresponding author: pzh@jaas.ac.cn

Abstract

In recent years, the annual demand for soft wheat in China has exceeded six million metric tons. The development of soft wheat is an important objective in the Yangtze River Basin winter wheat region in China. Ningmai 9 is a soft wheat cultivar widely used as a parent in the soft red winter wheat breeding program. However, the physicochemical and rheological properties of Ningmai 9 and its derivatives remain unknown. In this study, Ningmai 9 and its thirty-one derivatives were grown in Nanjing in Jiangsu Province in two successive cropping seasons from 2015 to 2017. The kernel samples were analyzed for milling quality, solvent retention capacity (SRC), alveograph parameters, and sugar-snap cookie diameter. The flour protein content was not significantly associated with any other quality trait. P, L, P/L (the ratio of tenacity to extensibility), alveograph deformation work (W), and four types of SRC were significantly correlated with sugar-snap cookie diameter. Compared to Ningmai 9 , seven wheat genotypes had relatively better cookie quality and lower SRC and P values. A multiple regression model with water SRC (WSRC) as a variable explained $72.5 \%$ of the total variation in cookie diameter. These results suggest that decreasing SRC and gluten strength is the key to improving soft wheat breeding programs.

Keywords: Common wheat, milling quality, solvent retention capacity, dough property, and cookie diameter.

Abbreviations: HARD_kernel hardness, FY_flour yield, BFY_break flour yield, FPC_flour protein content, ASH_ash content, SRC_solvent retention capacity, WSRC_water solvent retention capacity, SCSRC_sodium carbonate solvent retention capacity, LASRC_lactic acid solvent retention capacity, SUSRC_sucrose solvent retention capacity, P_alveograph tenacity, L_alveograph extensibility, W_alveograph deformation work.

\section{Introduction}

Wheat is a primary staple food crop worldwide and has specific quality requirements for particular end-uses, such as bread, cakes, biscuits and noodles. There are two basic market classes of wheat, hard wheat and soft wheat. Hard wheat flour has a high protein content and is characterized by strong gluten strength and high water absorption, which lead to increased mixing tolerance and bread volume; in contrast, soft wheat flour contains low amounts of protein and is characterized by reduced water absorption and small particle size, which improve the flow of dough and the texture of products associated with cakes, cookies, and crackers (Zhang et al., 2007a).

At the beginning of this century, Chinese scientists focused on improving the quality of steamed bread, noodles, western-style bread and other products of hard wheat (He et al., 2003, 2004). Many hard white wheat cultivars with good end-use quality have been released in northern China (Zhang et al., 2007b; Yang et al., 2014). In the last 15 years, the annual soft wheat consumption in China has expanded to more than six million metric tons. Improving the quality of soft wheat is a high priority in Chinese wheat production programs, especially those in the middle and lower reaches of the Yangtze River winter wheat region, the best region for soft red winter wheat production (He et al., 2002; Souza et al., 2012). However, the lack of germplasm and criteria for quality selection are the most important challenges in soft wheat breeding programs. Most soft wheat varieties with good cookie quality from the USA or Australia cannot be used as parents because their agronomic traits and resistance to biotic or abiotic stresses are not adapted to the local environment. Three Chinese varieties, Jianmai 1, Wanmai 48 and Wanmai 19, were once considered to have good cookie-making quality (cookie diameter $\geq 8.0 \mathrm{~cm}$ using AACC method 10-52), but none of them has been widely applied in wheat production. To date, only a few varieties, such as Ningmai 9 and Yangmai 13, are widely grown in China with high yield potential and good cookie-making quality. Ningmai 9, which has stable protein levels, acceptable dough extensibility and water absorption, shows the best cookie quality across variable environments (Zhang et al., 2016). As a founder parent, Ningmai 9 has produced more than 20 cultivars in the last 20 years (Jiang et al., 2016). However, the physicochemical and rheological properties and end-use quality of the derivatives of Ningmai 9 have not been studied, which are particularly interesting in soft wheat breeding programs in China. Therefore, the objectives of this 
study are 1) to evaluate the quality performance of Ningmai 9 and its 31 derivatives with soft kernel texture, 2) to identify potential germplasms for use as parents in soft wheat breeding, and 3) to identify the most important quality parameters in determining cookie-making quality.

\section{Results}

\section{Quality performance of Ningmai 9 wheat and its derivatives}

Analysis of variance showed that both year and genotype significantly affected all quality traits (Table S1). Year was the most important source of variance for most quality traits and could explain more than $90 \%$ of the total variance of kernel hardness, flour yield, flour protein content (FPC), sodium carbonate solvent retention capacity (SCSRC), lactic acid solvent retention capacity (LASRC), sucrose solvent retention capacity (SUSRC), and alveograph deformation work (W). Genotype contributed to more than $30 \%$ of the total variance of WSRC and alveograph $P$ and $L$. The genotype by year interaction significantly affected the ash content, LASRC, SUSRC, alveograph tenacity (P) and alveograph extensibility (L). Kernel hardness showed a narrow range of variation (Table 1). JS38 had the lowest hardness value, although it was derived from a hard $x$ soft cross (Table S1). The straight flour yield also showed a narrow range compared with the range of break flour yield. Ningmai 9 had the lowest protein content. Compared to Ningmai 9, most derivatives also had high values of SRC and alveograph P. All genotypes showed lower alveograph L values than $100 \mathrm{~mm}$ except for JS32. All genotypes with cookie diameters larger than those of Ningmai 9 were derived from the crosses between Ningmai 9 and the other three varieties, i.e., Ningmai 8, Yangmai 9 and Yangmai 15.

\section{Correlations among quality traits}

Correlations among quality traits were similar in each year. The correlation coefficients among the mean of quality traits across two years are shown in Table 2. FPC was not correlated with any of the other quality traits. Kernel hardness was positively correlated with straight flour yield $(P$ $<0.01)$ but negatively correlated with break flour yield $(P<$ $0.01)$. Flour yield was somewhat correlated with LASRC $(P<$ $0.05)$ and SUSRC $(P>0.05)$. The ash content significantly affected all four SRCs ( $r=0.35-0.49, P<0.05$ or 0.01 ) and sugar-snap cookie diameter $(r=-0.39, P<0.05)$. The four SRCs were highly correlated to the four alveograph parameters $(P<0.01)$. In addition to the ash content, the four SRCs and alveograph $P, P / L$, and $W$ were highly and negatively correlated, respectively, with sugar-snap cookie diameter $(r=-0.64--0.85, P<0.01)$. However, alveograph $\mathrm{L}$ showed a positive correlation with cookie diameter $(r=0.61$, $P<0.01)$. The multiple regression model with 5 variables, WSRC, alveograph P, SUSRC, SCSRC, and LASRC, explained $77.3 \%$ of the total variation in cookie diameter (Table $3, P<$ $0.5)$, but only WSRC was highly significant $(P<0.001)$. The alveograph test is not an economic and high-throughput screening method in breeding programs and could only explain $2.67 \%$ of the total variation in cookie diameter. Thus, the optimized model with only WSRC as the variable was $y=24.151-0.123 \times 1$, which explained $72.5 \%$ of the total variation in cookie diameter. In this model, $y$ is the sugarsnap cookie diameter $(\mathrm{cm}), 24.151$ is the intercept $(F=798.06$,
$P<0.0001)$, and $x_{1}$ is the WSRC $(F=79.07, P<0.0001)$.

\section{Genotypic classification based on cookie diameter}

Based on the cookie diameter, clustering analysis clearly showed three groups $(P<0.05$, Table 4 , Figure 1$)$. Group I included 8 genotypes, JS03, JS13, JS14, JS15, JS32, JS33, JS46, and JS47 (Ningmai 9), which had the lowest SRC values and alveograph $P, P / L$ and $W$ values, the highest alveograph $L$ value, and the largest cookie diameter. Group III, which included 11 genotypes, had the highest SRC values, the lowest alveograph $L$ value, and the lowest cookie diameter. There were significant differences among the three groups for WSRC, SCSRC, SUSRC, and alveograph P. However, kernel hardness, flour yield, break flour yield, flour protein, and flour ash were not significantly different among the three groups. All genotypes in Group I were derived from three wheat genotypes, Ningmai 8, Yangmai 9 and Yangmai 15, in addition to Ningmai 9. These three genotypes were also used as parents in several derivatives in Group II and Group III, indicating that both parent selection and progeny screening of quality traits are important in breeding programs.

\section{Discussion}

\section{Quality trait evaluation}

In this study, year was the most important source of variation for all quality traits. In a previous study on 17 Chinese soft cultivars, similar results were observed for the same quality traits except for kernel hardness, LASRC, and alveograph P (Zhang et al., 2007a). However, Guttieri et al. (2001) and Guttieri and Souza (2003) reported that genotype contributes more than environment does to variation in all four types of SRC. High-quality soft wheat desirably produces flour with low water absorption to make lowmoisture baked goods, cookies and crackers. SRCs are ideal diagnostic parameters (Kweon et al., 2014). Compared to the target SRC values for the soft wheats of eastern U.S. ( $\leq 51 \%$ for WSRC, $\leq 64 \%$ for SCSRC, $\leq 89 \%$ for SUSRC, and $\geq 87 \%$ for LASRC), the SRC values of the tested genotypes were high (Table 1 and Table S2). The average values of WSRC, SCSRC, SUSRC, and LASRC were $61.8 \%, 79.4 \%, 119.5 \%$, and $116.0 \%$, respectively, indicating high flour water absorption when the cookie dough was prepared and less spreading when the dough was baked, which resulted from a lack of total syrup (Kweon et al., 2014; Slade and Levine, 1994).

Kernel hardness is important for wheat market classification and greatly influences milling quality, which is controlled not only by allelic variation of the hardness locus $(\mathrm{Ha})$ and the total puroindoline content but also by the interaction between PINA and PINB (Morris, 2002; Hogg et al., 2004; Chen et al., 2006). In the current dataset, most genotypes exhibited single-kernel characterization system (SKCS) hardness index values higher than 30 , similar to another set of Chinese soft wheats (Zhang et al., 2007a). Previous studies have shown that extensive variation in kernel texture within the soft wheat class occurs universally (Morris et al., 2005, 2011). Thus, exploring and using novel germplasms is important in further improving kernel softness. In the current dataset, the average FPC was $11.5 \%$, which is higher than the optimum criterion (less than $10.0 \%$ ) for cookie 
Table 1. Mean and range for milling quality, solvent retention capacities, alveograph parameters, and cookie diameter of Ningmai 9 and thirty-one derivatives across two environments.

\begin{tabular}{|c|c|c|c|c|}
\hline Quality parameters & & Overall mean $^{+}$ & Cultivar range $(n=32)$ & Overall range $(n=64)$ \\
\hline \multirow[t]{5}{*}{ Milling quality } & Kernel hardness & $33.4 \pm 3.8$ & $28.4-38.3$ & $25.7-42.1$ \\
\hline & Straight-flour yield, \% & $67.1 \pm 7.1$ & $64.2-69.5$ & $58.0-76.5$ \\
\hline & Break flour yield, \% & $27.4 \pm 3.1$ & $22.5-31.6$ & $20.5-36.0$ \\
\hline & Ash content, \% & $0.38 \pm 0.05$ & $0.31-0.47$ & $0.28-0.51$ \\
\hline & Flour protein content, \%mb & $11.5 \pm 0.7$ & $10.6-12.4$ & $10.1-13.0$ \\
\hline \multirow[t]{4}{*}{ SRC } & Water SRC, \% & $61.8 \pm 2.8$ & $57.4-69.5$ & $56.8-70.2$ \\
\hline & Sodium carbonate SRC, \% & $79.4 \pm 6.1$ & $71.3-95.2$ & $68.6-101.9$ \\
\hline & Lactic acid SRC, \% & $116.0 \pm 13.4$ & $96.7-136.9$ & $94.5-146.2$ \\
\hline & Sucrose SRC, \% & $119.5 \pm 15.1$ & $108.5-137.1$ & $93.6-160.1$ \\
\hline \multirow[t]{4}{*}{ Alveograph } & Tenacity (P), mm & $86.3 \pm 20.3$ & $58.0-130.0$ & $51.0-134.0$ \\
\hline & Extensibility (L), mm & $73.7 \pm 14.8$ & $51.0-100.0$ & $45.0-130.0$ \\
\hline & Deformation work, $\times 10^{-4} \mathrm{~J}$ & $214.9 \pm 46.9$ & $131.1-303.0$ & $0.53-2.44$ \\
\hline & $P / L$ & $1.25 \pm 0.50$ & $0.60-2.30$ & $117.0-336.6$ \\
\hline Cookie quality & Cookie diameter, $\mathrm{cm}$ & $16.6 \pm 0.5$ & $15.9-17.2$ & $15.8-18.0$ \\
\hline
\end{tabular}

${ }^{+}$Mean \pm standard deviation.

Table 2. Correlation coefficients among milling quality, solvent retention capacity, alveograph parameters and sugar-snap cookie diameter.

\begin{tabular}{|c|c|c|c|c|c|c|c|c|c|c|c|c|c|}
\hline & \multicolumn{4}{|c|}{ Milling quality } & \multicolumn{4}{|l|}{ SRC } & \multicolumn{4}{|c|}{ Alveograph parameters } & \multirow{2}{*}{$\begin{array}{l}\text { Cookie } \\
\text { diameter }\end{array}$} \\
\hline & $\mathrm{FY}$ & $\mathrm{BFY}$ & FPC & Ash & WSRC & SCSRC & LASRC & SUSRC & $\mathrm{P}$ & $\mathrm{L}$ & $\mathrm{P} / \mathrm{L}$ & W & \\
\hline HARD & $0.47^{* *}$ & $-0.55^{* *}$ & 0.18 & 0.06 & 0.24 & 0.02 & 0.13 & -0.14 & 0.16 & -0.3 & 0.26 & 0.04 & -0.18 \\
\hline $\mathrm{FY}$ & & -0.29 & 0.20 & 0.02 & -0.01 & -0.11 & $-0.38^{*}$ & -0.36 & -0.23 & 0.09 & -0.17 & -0.32 & 0.15 \\
\hline BFY & & & -0.27 & $-0.37^{*}$ & -0.32 & -0.15 & -0.15 & -0.04 & -0.24 & 0.31 & -0.28 & -0.09 & 0.28 \\
\hline FPC & & & & 0.17 & 0.13 & 0.03 & 0.12 & 0.07 & 0.06 & -0.02 & 0.03 & 0.12 & -0.07 \\
\hline ASH & & & & & $0.43^{*}$ & $0.41^{*}$ & $0.35^{*}$ & $0.49^{* *}$ & 0.21 & -0.13 & 0.18 & 0.24 & $-0.39^{*}$ \\
\hline WSRC & & & & & & $0.94^{* *}$ & $0.67^{* *}$ & $0.80^{* *}$ & $0.82^{* *}$ & $-0.64^{* *}$ & $0.77^{* *}$ & $0.66^{* *}$ & $-0.85^{* *}$ \\
\hline SCSRC & & & & & & & $0.61^{* *}$ & $0.85^{* *}$ & $0.76^{* *}$ & $-0.55^{* *}$ & $0.69^{* *}$ & $0.63^{* *}$ & $-0.80^{* *}$ \\
\hline LASRC & & & & & & & & $0.74^{* *}$ & $0.79^{* *}$ & $-0.59^{* *}$ & $0.77^{* *}$ & $0.77^{* *}$ & $-0.64^{* *}$ \\
\hline SUSRC & & & & & & & & & $0.75^{* *}$ & $-0.59^{* *}$ & $0.72^{* *}$ & $0.63^{* *}$ & $-0.77^{* *}$ \\
\hline$P$ & & & & & & & & & & $-0.72^{* *}$ & $0.93^{* *}$ & $0.89^{* *}$ & $-0.79^{* *}$ \\
\hline L & & & & & & & & & & & $-0.89^{* *}$ & $-0.39^{*}$ & $0.61^{* *}$ \\
\hline$P / L$ & & & & & & & & & & & & $0.71^{* *}$ & $-0.75^{* *}$ \\
\hline W & & & & & & & & & & & & & $-0.66^{* *}$ \\
\hline
\end{tabular}

Table 3. Variables used in the multiple regression model for determining the cookie diameter.

\begin{tabular}{lllll}
\hline Variable entered & Partial R & Model R & F value & P value \\
\hline WSRC & 0.7249 & 0.7249 & 79.07 & $<0.0001$ \\
P & 0.0267 & 0.7516 & 3.11 & 0.0882 \\
SUSRC & 0.0113 & 0.7629 & 1.33 & 0.2583 \\
SCSRC & 0.0043 & 0.7672 & 0.50 & 0.4839 \\
LASRC & 0.0056 & 0.7728 & 0.64 & 0.4308 \\
\hline
\end{tabular}

All variables listed in the table met the significance requirement of $P \leq 0.50$. 
Table 4. Clustering of genotype based on the cookie diameter.

\begin{tabular}{|c|c|c|c|c|c|c|c|c|c|c|c|c|c|c|}
\hline Groups & HARD & $\begin{array}{l}\mathrm{FY}, \\
\%\end{array}$ & $\begin{array}{l}\text { BFY, } \\
\%\end{array}$ & $\begin{array}{l}\text { FPC, } \\
\%\end{array}$ & $\begin{array}{l}\text { ASH, } \\
\%\end{array}$ & $\begin{array}{l}\text { WSRC, } \\
\%\end{array}$ & $\begin{array}{l}\text { SCSRC, } \\
\%\end{array}$ & $\begin{array}{l}\text { LASRC, } \\
\%\end{array}$ & $\begin{array}{l}\text { SUSRC, } \\
\%\end{array}$ & $\begin{array}{l}\mathrm{P}, \\
\mathrm{mm}\end{array}$ & $\begin{array}{l}\mathrm{L}, \\
\mathrm{mm}\end{array}$ & $\mathrm{P} / \mathrm{L}$ & $\begin{array}{l}\text { W, } \\
\times 10^{-4} \mathrm{~J}\end{array}$ & $\begin{array}{l}\text { Cookie } \\
\text { diameter, } \\
\mathrm{cm}\end{array}$ \\
\hline 1 & $33.3 a$ & $67.9 a$ & $28.7 a$ & $11.6 \mathrm{a}$ & $0.35 b$ & $58.7 c$ & $73.9 c$ & $106.0 \mathrm{~b}$ & $111.7 \mathrm{c}$ & $67.0 c$ & $86.0 a$ & $0.80 \mathrm{~b}$ & $182.9 \mathrm{~b}$ & $17.1 \mathrm{a}$ \\
\hline II & $32.5 a$ & $66.7 \mathrm{a}$ & $27.4 a b$ & $11.4 a$ & $0.38 a b$ & $61.4 \mathrm{~b}$ & $79.0 \mathrm{~b}$ & $113.8 \mathrm{~b}$ & $119.0 \mathrm{~b}$ & $78.1 b$ & $78.4 a$ & $1.02 \mathrm{~b}$ & $198.8 \mathrm{~b}$ & $16.6 \mathrm{~b}$ \\
\hline III & $34.2 a$ & $66.9 a$ & $27.0 \mathrm{~b}$ & $11.7 \mathrm{a}$ & $0.39 a$ & $63.8 a$ & $82.6 a$ & $123.3 a$ & $124.3 a$ & $103.2 \mathrm{a}$ & $64.0 \mathrm{~b}$ & $1.68 \mathrm{a}$ & $244.7 a$ & $16.2 \mathrm{c}$ \\
\hline
\end{tabular}

Different letters in the same column indicate significance at $P \leq 0.05$.

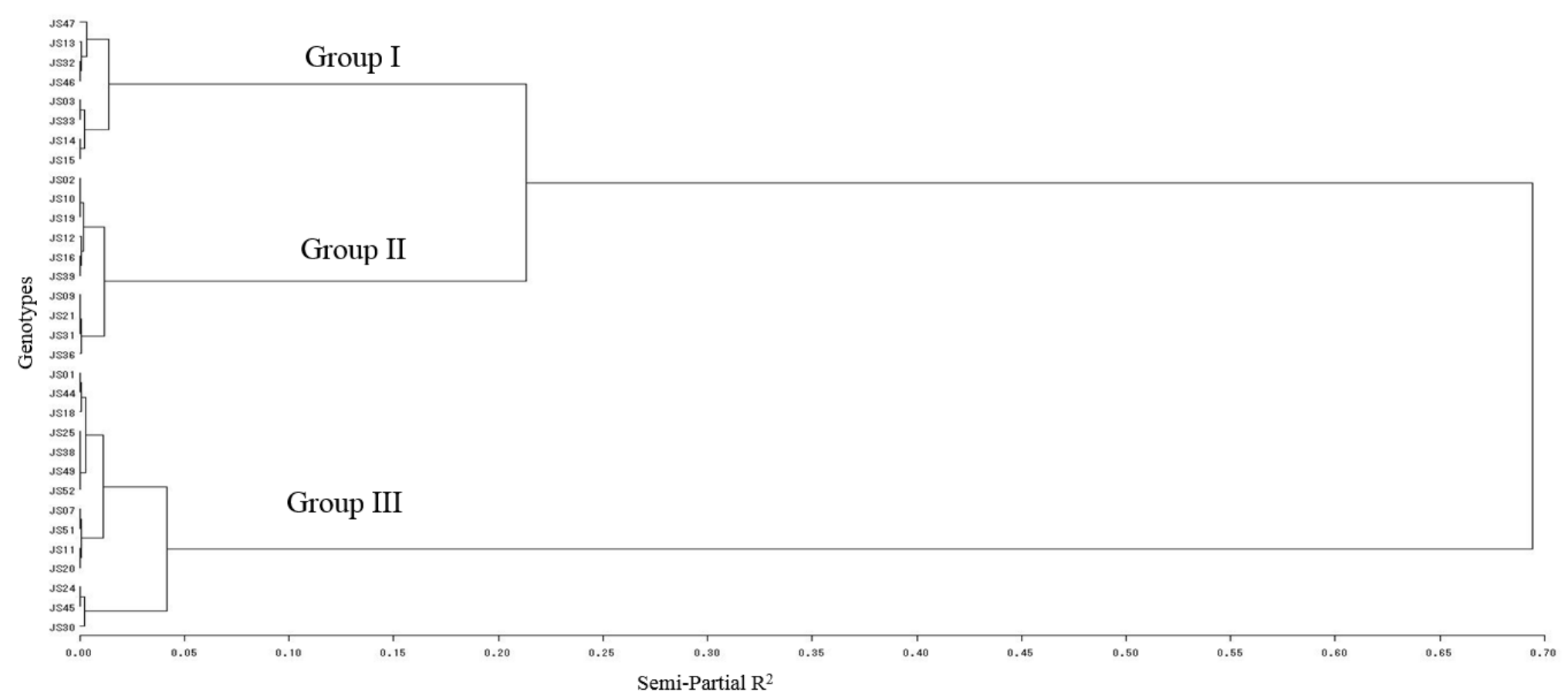

Fig 1. Cluster analysis of tested genotypes using Ward's method based on the mean cookie diameter across two years. 
baking. According to the field practices in this study, the nitrogen rate was $225 \mathrm{~kg} \mathrm{ha}^{-1}$, and thirty percent of total nitrogen was applied at stem elongation to obtain a high grain yield. This nitrogen application strategy is common in the Yangtze River Basin winter wheat region and increases nitrogen use efficiency, kernel yield and kernel protein content (Sowers et al., 1994; Lu et al., 2006; Yi et al., 2015). Thus, one challenge for soft wheat production is to balance the kernel yield and protein content based on acceptable end-use quality. Advanced fertilizer management methodologies should be further studied. The alveograph $\mathrm{P}$ and $W$ values were high, i.e., $86.3 \mathrm{~mm}$ and $214.9 \times 10^{-4} \mathrm{~J}$, respectively. However, the alveograph $L$ value was lower than $100 \mathrm{~mm}$ for most genotypes. Glutenin subunit deletion might be a promising way to decrease gluten elasticity and increase gluten extensibility at the same time (Jondiko et al., 2012; Zhang et al., 2014).

Seven wheat genotypes, i.e., JS03, JS13, JS14, JS15, JS32, JS33, and JS46, showed larger cookie diameters (17.0-17.25 $\mathrm{cm}$ ) than that of Ningmai 9 . Although elite soft wheat can be bred by interclass hybridization between soft and hard wheat (Kongraksawech et al., 2014), all seven genotypes (Group I) were bred by crossing Ningmai 9 and a few soft genotypes, i.e., Ningmai 8, Yangmai 9 and Yangmai 15. In fact, Yangmai 9 has been reported to have high cookie-making quality (Zhang et al., 2007a). Improving the end-use quality of new derivatives of Ningmai 9 requires knowledge of more genetic factors for improving kernel hardness, protein content, and gluten properties.

\section{Parameters used for determining snap cookie quality}

SRC is generally highly correlated with the cookie diameter and alveograph parameters (Ram and Singh., 2004; Guttieri et al., 2004). In this study, SRC was more sensitive than other quality parameters in differentiating the end-use quality of soft wheat. WSRC provides a summary of the general solvent retention capacity and is affected by all hydrophilic components in flour (Guttier and Souza, 2003). Although there were significant correlations between alveograph parameters and cookie diameter, WSRC was extremely important and explained $72.5 \%$ of the total variation in cookie diameter in the optimum multiple regression model. This result indicated that WSRC is a crucial parameter to for predicting cookie diameter in a soft wheat breeding program.

In this study, kernel hardness was significantly correlated with straight-grade flour yield and break flour yield. As described by Finney and Bains (1999), softer wheat produces more break flour than harder wheat does, and break flour yield is a highly reliable and discriminatory descriptor of grain texture. An ideal combination would be high straightgrade and break flour yield with less starch damage and small flour particle size, which would result in low water absorption and high commercial profit (Zhang et al., 2007a; Souza et al., 2012). Although straight-grade yield and break flour yield were negatively correlated $(r=-0.29, P>0.05)$, the values of these two parameters were high for some genotypes, such as Ningmai 9, JS13, JS14, JS33, and JS51. However, in this study, kernel hardness did not significantly affect cookie diameter $(r=-0.18, P>0.05)$. The same result has been reported in the other Chinese wheat cultivars (Zhang et al, 2007a). Different results have been reported in other soft wheat germplasm pools (Guttieri et al., 2001;
Gaines, 2000) and in one biparental recombinant inbred line population derived from the cross of soft $\times$ hard wheat (Campbell et al., 2011).

Low protein content in soft wheat can prevent the formation of a strong gluten network, which would allow dough to spread more during baking (Slade and Levine, 1994). Guttieri et al. (2001) found that within a narrow range $(9.6 \%$ to $10.6 \%)$, FPC was highly and negatively correlated with cookie diameter. However, in this study, FPC was independent of all quality traits. Similar results were also observed in other sets of genotypes (Geng et al., 2012; Pasha et al., 2009). This difference might result from the variable composition and quantity of gluten protein fractions (Zhang et al., 2007b). In this study, kernel quality was initially identified by visual inspection. The protein content and gluten properties were randomly combined. Those genotypes with the same FPC showed significant differences in gluten strength and enduse quality. For example, 'JS18' and 'JS46' had similar protein contents, but their alveograph $\mathrm{P}$ values were 112 $\mathrm{mm}$ and $63 \mathrm{~mm}$, and their cookie diameters were $16.3 \mathrm{~cm}$ and $17.1 \mathrm{~cm}$. Traditionally, protein composition is not important in soft wheat with a low protein content (Ma et al., 2019). However, some studies showed that soft wheat quality is significantly affected by not only the composition but also the quantity of glutenin subunits (Labuschagne and van Deventer, 1995; Hou et al., 1996; Ma et al., 2019; Zhang et al., 2016). Dough strength and extensibility should be synergistically improved to achieve acceptable end-use quality. In this regard, glutenin subunit composition related to weak gluten strength is strongly suggested.

\section{Materials and Methods}

\section{Wheat samples}

Ningmai 9 and its 31 derivatives were used in this study (Table S2). All wheat genotypes originated from traditional breeding programs based on agronomic performance and visual inspection of wheat kernels during the last 15 years. Grain with opaque, chalky, and mealy endosperm is usually assumed to be soft wheat with good quality. In addition to Ningmai 9, the parents of 31 derivatives included 10 other red winter wheat varieties. Ningmai 8, Yangmai 9, Yangfu 2 and Yangmai 15 are soft wheats. However, Yangmai 158, Yangmai 11, Yangmai 10, Yang 99G70, Ning 98077, Ningmai 12 and Sumai 6 are hard wheats. All genotypes were grown during two successive wheat seasons from 2015 to 2017 in Nanjing, which is the representative location in the middle and lower reaches of the Yangtze River Basin winter wheat region. A field experiment was conducted in a randomized complete block design with two replicates. All plots were managed according to local practices. The same application rates of $\mathrm{N}, \mathrm{P}_{2} \mathrm{O}_{5}$ and $\mathrm{K}_{2} \mathrm{O}$ were applied in both seasons: 225 $\mathrm{kg} \mathrm{ha}^{-1}, 112 \mathrm{~kg} \mathrm{ha}^{-1}$, and $112 \mathrm{~kg} \mathrm{a}^{-1}$, respectively. The split application of nitrogen fertilizer was $50 \%$ at sowing, $20 \%$ at tillering and $30 \%$ at stem elongation.

\section{Quality testing}

Grain hardness was tested using a single-kernel characterization system (SKCS 4100, Perten Instruments North America Inc., Springfield, IL), and all samples exhibited a soft texture. The kernel samples were tempered to $14.5 \%$ moisture content and milled into flour using a Bühler 
laboratory mill (Bühler MLU 202, Bühlur Inc., Uzwil, Switzerland) according to AACC 26-31. The straight-grade flour yield was approximately $65 \%$, and the break flour yield was calculated. The FPC and ash content were determined with a near-infrared (NIR) spectroscopy analyzer (Perten DA 7200, Perten Instruments, Stockholm, Sweden). The SRC was determined according to AACC 56-11, which included WSRC, SCSRC, lactic LASRC, and SUSRC. The alveograph parameters were determined using an Alveograph NG instrument (Chopin, France) (tenacity $P$, extensibility $L, P / L$, and deformation work W) according to AACC 54-30A. Sugar-snap cookie diameter was noted according to AACC 10-52.

\section{Statistical analysis}

Analysis of variance (ANOVA) was performed using PROC GLM for all quality traits (SAS Institute, 1997), treating genotype as a fixed effect, with year and year-related interactions and replication nested in years as random effects. Fisher's F-protected least significant difference (LSD) method was used to separate means. Genotypic least square means were calculated and used for subsequent analysis. Pearson's linear correlation coefficients among quality parameters were obtained by PROC CORR. Multiple regression analysis was conducted by PROC REG with cookie diameter as the dependent variable, while the other quality traits were used as independent variables to fit the model with the optimized $\mathrm{R}^{2}$ value using model SELECTION=FORWARD. Genotypic classification based on cookie diameter was conducted using PROC CLUSTER with Ward's method. ANOVA was conducted with cluster as a variable; cluster was treated as a fixed effect, while genotypes nested in cluster and year were treated as random. The derived mean cookie diameter for each cluster was used to test levels of significance.

\section{Conclusion}

Genotype and year significantly affected all quality traits, and year was the most important source of variation. The cookie-making quality of seven derivatives, i.e., JS03, JS13, JS14, JS15, JS32, JS33, and JS46, was better than that of Ningmai 9. Yangmai 9, Ningmai 8 and Yangmai 15 were good candidate parents for improving sugar-snap cookie quality. The solvent retention capacity and alveograph parameters were the most important traits in determining cookiemaking quality, and the water solvent retention capacity was the most important indicator of sugar-snap cookie-making quality of soft wheats.

\section{Acknowledgments}

Financial support was partially provided by the National Natural Science Foundation of China (31671690), the Natural Science Foundation of Jiangsu Province (BK20161375), the Key Project for the Research and Development of Jiangsu Province (BE2018399-1), and the indigenous innovation foundation of Jiangsu provincial agricultural science and technology (CX(18)1001).

\section{References}

AACC International (2002) Approved Methods of Analysis (11th ed). AACCI, St Paul, MN.
Campbell KG, Finney PL, Bergman CJ, Gualberto DG, Anderson JA, Giroux MJ, Siritunga D, Zhu JQ, Gendre F, Roue C, Verel, A, Sorrells ME (2011) Quantitative trait loci associated with milling and baking quality in a softxhard wheat cross. Crop Sci. 41 (4):1275-1285.

Chen F, He ZH, Xia XC, Xia LQ, Zhang XY, Lillemo M, Morris CF (2006) Molecular and biochemical characterization of puroindoline $a$ and $b$ alleles in Chinese landraces and historical cultivars. Theor. Appl. Gene. 112 (3):400-409.

Finney PL, Bains GS (1999) Protein functionality differences in eastern U.S. soft wheat cultivars and interrelation with end-use quality tests. LWT-Food Sci Technol. 32 (7): 406415.

Gaines CS (2000) Collaborative study of methods for solvent retention capacity profile (AACC Method 56-11). Cereal Foods World. 45 (7): 303-306.

Geng ZM, Zhang PP, Yao JB, Yang D, Ma HX, Rayas-Duarte P (2012) Physicochemical and rheological properties of Chinese soft wheat flours and their relationships with cookie-making quality. Cereal Chem. 89 (5): 237-241.

Guttieri MJ, Souza E (2003) Sources of variation in the solvent retention capacity test of wheat flour. Crop Sci. 43 (5): 1628-1633.

Guttieri MJ, Becker C, Souza EJ (2004) Application of wheat meal solvent retention capacity tests within soft wheat breeding populations. Cereal Chem. 81 (2): 261-266.

Guttieri MJ, Bowen D, Gannon D, O'Brien K, Souza EJ (2001) Solvent retention capacities of irrigated soft white spring wheat flours. Crop Sci. 41 (4): 1054-1061.

He ZH, Lin ZJ, Wang LJ, Xiao ZM, Wan FS, Zhuang QS (2002) Classification on Chinese wheat regions based on quality. Sci Agric Sin. 35 (4): 359-364.

He ZH, Liu AH, Peña RJ, Rajaram S (2003) Suitability of Chinese wheat cultivars for production of northern style Chinese steamed bread. Euphytica. 131 (2): 155-163.

He ZH, Yang J, Zhang Y, Quail KJ, Peña RJ (2004) Pan bread and dry white Chinese noodle quality in Chinese winter wheats. Euphytica. 139 (3): 257-267.

Hogg AC, Sripo T, Beecher B, Martin JM, Giroux MJ (2004) Wheat puroindolines interact to form friabilin and control wheat grain hardness. Theor Appl Genet. 108 (6): 10891097.

Hou G, Yamamoto H, Ng PKW (1996) Relationships of quantity of glutenin subunits of selected U.S. soft wheat flours to rheological baking properties. Cereal Chem. 73 (3): 352-357.

Jiang P, Zhang PP, Zhang X, Ma H X (2016) Genetic contribution of Ningmai 9 wheat to its derivatives evaluated by using SNP markers. Int J Genom. 3602986, http://dx.doi.org/10.1155/2016/3602986

Jondiko TO, Alviola NJ, Hays DB, Ibrahim A, Tilley M, Awika JM (2012) Effect of high-molecular-weight glutenin subunit allelic composition on wheat flour tortilla quality. Cereal Chem. 89 (3): 155-161.

Kongraksawech T, Ross AS, Peterson CJ (2014) Unexpectedly good soft wheat quality from a hardxsoft cross. Cereal Chem. 91 (6): 595-602.

Kweon M, Slade L, Levine H, Gannon D (2014) Cookie versus cracker-baking-What's the difference? Flour functionality requirements explored by SRC and alveograph. Crit Rev Food Sci. 54 (1): 115-138.

Labuschagne MT, van Deventer CS (1995) The effect of GluB1 high molecular weight glutenin subunits on biscuitmaking quality of wheat. Euphytica. 83 (3): 193-197. 
Lu ZG, Dai TB, Jiang D, Jing Q, Qin XD, Cao WX (2006) Effects of different nitrogen rates and dressing ratios on grain yield and quality in weak-gluten wheat. J Triticeae Crops. 26 (6): 75-80.

Ma F, Kim J, Cho E, Brown-Guedira G, Park CS, Baik BK (2019) HMW-GS composition and rye translocations of U.S. eastern soft winter wheat and their associations with protein strength. J Cereal Sci. 89: 102799

Morris CF (2002) Puroindolines: the molecular genetic basis of wheat grain hardness. Plant Mol Biol. 48 (5):633-647.

Morris CF, Anderson JA, King GE, Bettge AD, Campbell KG, Allan RE, Fuerst EP, Beecher BS (2011) Characterization of a unique "super soft" kernel trait in wheat. Cereal Chem. 88 (6):576-583.

Morris CF, Campbell KG, King GE (2005) Kernel texture differences among U.S. soft wheat cultivars. J Sci Food Agric. 85 (11):1959-1965.

Pasha I, Anjum FM, Butt MS (2009) Genotypic variation of spring wheats for solvent retention capacities in relation to end-use quality. LWT-Food Sci Technol. 42 (1):418-423.

Ram S, Singh RP (2004) Solvent retention capacities of Indian wheats and their relationship with cookie-making quality. Cereal Chem. 81 (1):128-133.

Slade L, Levine H (1994) Structure-function relationships of cookie and cracker ingredients. In: The Science of Cookie and Cracker Production, pp. 23-141. Faridi H, Ed., Chapman \& Hall, New York.

Souza EJ, Sneller C, Guttieri MJ, Sturbaum A, Griffey C, Sorrells M, Ohm H, Van Sanford D (2012) Basis for selecting soft wheat for end-use quality. Crop Sci. 52 (1):21-31.
Sowers KE, Miller BC, Pan WL (1994) Optimizing yield and grain protein in soft white winter wheat with split nitrogen applications. Agron J. 86 (6):1020-1025.

Yang XS, Wu L, Zhu ZH, Ren GX, Liu SC (2014) Variation and trends in dough rheological properties and flour quality in 330 Chinese wheat varieties. Crop J. 2 (4):195-200.

Yi Q, He P, Zhang XZ, Yang L, Xiong GY (2015) Optimizing fertilizer nitrogen for winter wheat production in Yangtze river region in China. J Plant Nutr. 38 (11):1639-1655.

Zhang QJ, Zhang Y, Zhang Y, He ZH, Peña RJ (2007a) Effects of solvent retention capacities, pentosan content, and dough rheological properties on sugar snap cookie quality in Chinese soft wheat genotypes. Crop Sci. 47 (2):656-664.

Zhang PP, He ZH, Zhang Y, Zhang Y, Xia XC (2007b) Pan bread and Chinese white salted noodle qualities of Chinese winter wheat cultivars and their relationship with gluten protein fractions. Cereal Chem. 84 (4):370-378.

Zhang PP, Jondiko TO, Tilley M, Awika JM (2014) Effect of high molecular weight glutenin subunit composition in common wheat on dough properties and steamed bread quality. J Sci Food Agric. 94 (13):2801-2806.

Zhang PP, Ma HX, Yao JB, Zhou MP, Zhang P (2016) Effect of HMW-GS deletion on processing quality of soft wheat Ningmai 9. Acta Agron Sin. 42 (5):633-640. 